\title{
Effect of Au Film Thickness and Surface Roughness on Room-Temperature Wafer Bonding and Wafer-Scale Vacuum Sealing by Au-Au Surface Activated Bonding
}

\author{
Michitaka Yamamoto ${ }^{1,2}$ (D), Takashi Matsumae ${ }^{2}$ (D), Yuichi Kurashima ${ }^{2}$, Hideki Takagi ${ }^{2}$, \\ Tadatomo Suga $^{3}$, Seiichi Takamatsu ${ }^{1}$, Toshihiro Itoh ${ }^{1}$ and Eiji Higurashi ${ }^{2, *}$ (D) \\ 1 The University of Tokyo, 5-1-5 Kashiwanoha, Kashiwa-shi, Chiba 277-8563, Japan; \\ myamamoto@s.h.k.u-tokyo.ac.jp (M.Y.); seiichi-takamatsu@edu.k.u-tokyo.ac.jp (S.T.); \\ toshihiro-itoh@edu.k.u-tokyo.ac.jp (T.I.) \\ 2 National Institute of Advanced Industrial Science and Technology (AIST), 1-2-1 Namiki, Tsukuba, \\ Ibaraki 305-8564, Japan; t.matsumae@aist.go.jp (T.M.); y-kurashima@aist.go.jp (Y.K.); \\ takagi.hideki@aist.go.jp (H.T.) \\ 3 Meisei University, 2-1-1 Hodokubo, Hino, Tokyo 191-8506, Japan; suga@gakushikai.jp \\ * Correspondence: eiji.higurashi@aist.go.jp
}

Received: 20 March 2020; Accepted: 24 April 2020; Published: 27 April 2020

\begin{abstract}
Au}-\mathrm{Au}$ surface activated bonding (SAB) using ultrathin $\mathrm{Au}$ films is effective for room-temperature pressureless wafer bonding. This paper reports the effect of the film thickness $(15-500 \mathrm{~nm})$ and surface roughness $(0.3-1.6 \mathrm{~nm})$ on room-temperature pressureless wafer bonding and sealing. The root-mean-square surface roughness and grain size of sputtered $\mathrm{Au}$ thin films on $\mathrm{Si}$ and glass wafers increased with the film thickness. The bonded area was more than $85 \%$ of the total wafer area when the film thickness was $100 \mathrm{~nm}$ or less and decreased as the thickness increased. Room-temperature wafer-scale vacuum sealing was achieved when Au thin films with a thickness of $50 \mathrm{~nm}$ or less were used. These results suggest that Au-Au SAB using ultrathin Au films is useful in achieving room-temperature wafer-level hermetic and vacuum packaging of microelectromechanical systems and optoelectronic devices.
\end{abstract}

Keywords: heterogeneous integration; wafer bonding; wafer sealing; room-temperature bonding; $\mathrm{Au}-\mathrm{Au}$ bonding; surface activated bonding; Au film thickness; surface roughness

\section{Introduction}

Sealing techniques are essential to protect the sensitive elements of microelectromechanical systems (MEMS) and optoelectronic devices from the environment [1-3]. An effective way to achieve sealing is to bond cap wafers to device wafers. Many types of bonding techniques such as anodic bonding [4], thermocompression bonding [5-7], solder bonding [8,9], and eutectic bonding [10] have been used as sealing techniques. However, these techniques require high bonding temperature, which causes problems such as thermally induced mechanical stress due to thermal expansion mismatch. Therefore, low-temperature bonding using metal intermediate layers is becoming increasingly attractive because of the high bonding strength and good reliability that can now be achieved. Research on bonding using Au intermediate layers has been increasing [11-35], because Au has several highly desirable properties such as high resistance to oxidation and corrosion.

$\mathrm{Au}-\mathrm{Au}$ surface activated bonding $(\mathrm{SAB})$ [17-35] is a promising technique for low-temperature bonding. In $\mathrm{Au}-\mathrm{Au} \mathrm{SAB}$, the $\mathrm{Au}$ surfaces are activated by plasma treatment and then brought into 
contact at low temperature $\left(<150^{\circ} \mathrm{C}\right)$. Au-Au SAB has also been applied to hermetic sealing, as well as the integration of different materials $[17,24]$. An advantage of Au-Au SAB is that the Au films can be patterned using photolithography before bonding, enabling high transparency to be achieved by using glass wafers [35]. For example, chip-scale hermetic sealing in air has been achieved at low temperature $\left(150{ }^{\circ} \mathrm{C}\right)$. However, high bonding pressure (300 MPa) was necessary because thick Au films (thickness: 300-500 $\mathrm{nm}$ ) with rough surfaces (root mean square (RMS) surface roughness: $4.0 \mathrm{~nm}$ ) were used as sealing rings [24]. Various methods such as thermal-imprint [25], lift-off [26], and direct-transfer [31] have been investigated to reduce the bonding pressure required for sealing by using Au-Au SAB. However, high bonding pressure (>100 MPa) is still required to achieve sealing [28].

Room-temperature pressureless wafer bonding was recently achieved with Au-Au SAB using ultrathin Au films (thickness $<50 \mathrm{~nm}$ ) with small grains, and thus, smooth surfaces (RMS surface roughness: $<0.5 \mathrm{~nm}$ ) [30,34]. Furthermore, room-temperature pressureless wafer-scale hermetic sealing in both air and vacuum was achieved using Au-Au SAB with ultrathin Au films (thickness: $15 \mathrm{~nm}$ ) [35]. However, the effect of the film thickness on $\mathrm{Au}-\mathrm{Au}$ bondability and sealing quality has not been investigated quantitatively.

This paper reports on the use of $\mathrm{Au}$ thin films with different film thicknesses in room-temperature pressureless wafer bonding and vacuum sealing processes. We also investigate the effect of film thickness and surface roughness on wafer bonding and vacuum sealing quality.

\section{Experimental Methods}

\subsection{Room-Temperature Pressureless Wafer Bonding in Ambient Air}

In the first experiment, Au thin films with different thicknesses $(15,50,100,300,500 \mathrm{~nm})$ and Ti thin films with a thickness of $5 \mathrm{~nm}$ as adhesion layers were deposited on 4-inch Si wafers by DC sputtering (JSP-8000, ULVAC, Inc., Chigasaki, Japan). The sputtering was performed at a chamber pressure of $0.15 \mathrm{~Pa}$ and a sputtering power of $200 \mathrm{~W}$ for the Ti films and $100 \mathrm{~W}$ for the Au films. The surface roughness of the deposited films was measured with an atomic force microscope (AFM; L-trace, Hitachi High-Tech Science Corporation, Tokyo, Japan), with a scanning area of $500 \mathrm{~nm} \times 500 \mathrm{~nm}$. The average grain size of the $\mathrm{Au}$ films was calculated from the observed AFM data using the watershed algorithm [36]. To investigate the stress in the deposited films, we measured the curvature radius of the wafers before and after film deposition using a thin-film stress measurement system (FLX-2320-S, TOHO Inc., Nagoya, Japan). The film stress $\sigma_{f}$ was calculated using the Stoney equation [37]:

$$
\sigma_{f}=\frac{E_{s} t_{s}^{2}}{6\left(1-v_{s}\right) t_{f}} \cdot\left(\frac{1}{R_{1}}-\frac{1}{R_{0}}\right)
$$

where $E_{s}, v_{s}$, and $t_{s}$, are Young's modulus, Poisson's ratio, and substrate thickness, respectively, $R_{0}$ and $R_{1}$ are the curvature radii of the wafer before and after film deposition, and $t_{f}$ is the deposited film thickness. In this work, Si was assumed to be isotropic, and Young's modulus, Poisson's ratio, and substrate thickness were set to $169 \mathrm{GPa}, 0.06$, and $525 \mu \mathrm{m}$, respectively [38,39]. The $t_{f}$ was calculated as the total thickness of the Au and Ti thin films.

The bonding was performed by placing two wafers with the Au sides facing each other in ambient air and squeezing their centers together with tweezers once with an estimated applied force of $<10 \mathrm{~N}$. Before bonding, Ar plasma treatment (RF power: $200 \mathrm{~W}$, operating pressure: $60 \mathrm{~Pa}$, treatment time: $60 \mathrm{~s}$ ) was performed for surface activation using the plasma equipment installed in the bonding system (WAP-1000, Bondtech Co., Ltd., Kyoto, Japan). The treatment time (60 s) was short enough not to affect the surface roughness of the Au surfaces [34]. The bonded area was observed with a surface acoustic microscope (SAM; SAM 300, PVA TePla Analytical Systems, Westhausen, Germany), and the percentage of the bonded area was calculated using ImageJ software [40]. The bonding strength was evaluated using the razor blade test, which is also known as the crack opening method [41]. The crack length caused by inserting a blade was observed with the SAM. 


\subsection{Room-Temperature Wafer Sealing in Vacuum}

In the second experiment, Au thin films with different film thicknesses (15, 50, 100, $300 \mathrm{~nm})$ and Ti thin films with a thickness of $5 \mathrm{~nm}$ as adhesion layers were deposited on Si wafers (4-inch diameter) with cavities and on alkali-free ultrathin glass wafers ( $80 \mathrm{~mm}$ square and $50 \mu \mathrm{m}$ thick, G-Leaf, Nippon Electric Glass Co., Ltd., Otsu, Japan) by DC sputtering. More than 100 cavities with lateral dimensions of $2 \mathrm{~mm} \times 2 \mathrm{~mm}$, a depth of $100 \mu \mathrm{m}$, and a pitch of $3 \mathrm{~mm}$ were fabricated in the middle of the wafers by wet chemical etching. A schematic of a bonded wafer pair is shown in Figure $1 \mathrm{a}$, and a cross-sectional schematic of a vacuum-sealed sample is shown in Figure 1b. The surface roughness of each wafer was measured with the AFM, and the average grain size was calculated using the watershed algorithm.

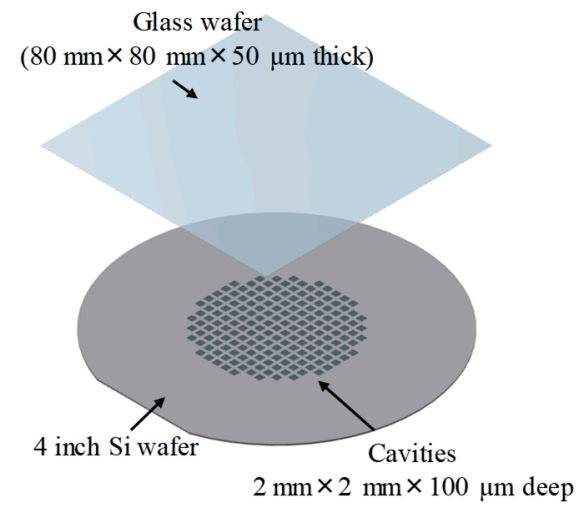

(a)

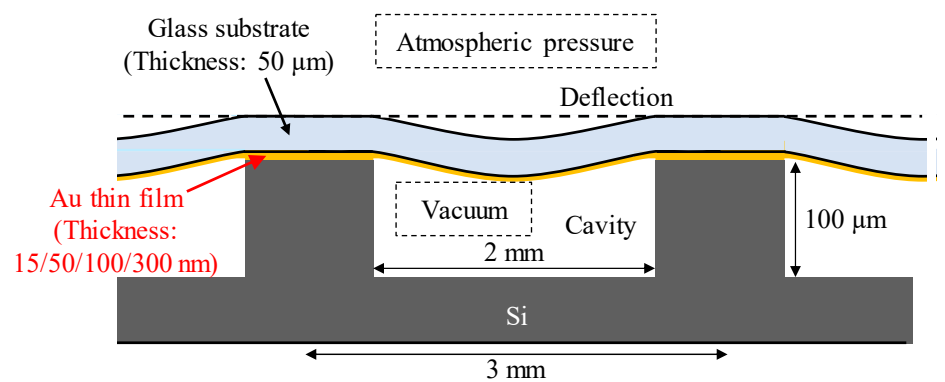

(b)

Figure 1. Schematics of bonded wafer pair and bonded structure: (a) Wafer pair (thin glass wafer and Si wafer with cavities) deposited with Au thin films (b) Cross-sectional schematic of vacuum-sealed sample. Glass substrate exhibited deflection due to pressure difference between sealed vacuum cavity and ambient atmosphere.

Room-temperature vacuum sealing was performed using the bonding system (WAP-1000, Bondtech Co., Ltd.). Two wafers were bonded in a vacuum chamber $\left(\sim 10^{-2} \mathrm{~Pa}\right)$ at room temperature and a contact load of 2000 N. Before bonding, the Au surfaces were activated by Ar plasma (RF power: $200 \mathrm{~W}$, operating pressure: $60 \mathrm{~Pa}$, treatment time: $60 \mathrm{~s})$. The applied contact load $(2000 \mathrm{~N})$ corresponded to less than 1.6 MPa for the bonded samples.

The sealing quality of the vacuum-sealed samples was evaluated by visually checking the number of cavities with cap deflection. Since the glass wafers were thin (thickness: $50 \mu \mathrm{m}$ ), the glass caps on the vacuum-sealed cavities exhibited deflection after bonding due to the pressure difference between the sealed vacuum cavities and the ambient atmosphere, as shown in Figure 1b. Furthermore, microstructure observation of the bonded interface was performed with a transmission electron microscope (TEM; H-9500, Hitachi High-Tech Science Co., Tokyo, Japan). 


\section{Results}

\subsection{Room-Temperature Pressureless Wafer Bonding in Ambient Air}

A measured AFM image of a Si wafer before $\mathrm{Au}$ thin film deposition is shown in Figure 2a, and the images of $\mathrm{Au}$ thin films with thicknesses of 15,50, 100, 300, and $500 \mathrm{~nm}$ deposited on Si wafers are shown in Figure 2b-f, respectively. Before film deposition, the RMS surface roughness was $0.3 \mathrm{~nm}$. The grain geometry of each Au thin film (Figure 3) was determined using the watershed algorithm. The effect of the film thickness on the surface roughness and average grain size deposited on the Si wafers is illustrated in Figure 4. Both increased exponentially with the thickness, which is consistent with the results of previous studies [42].

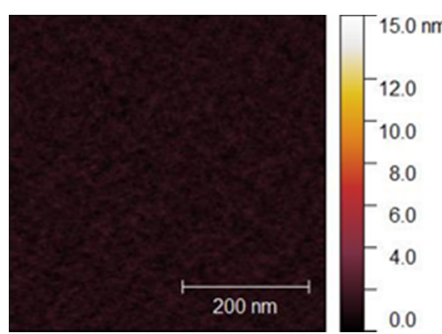

(a)

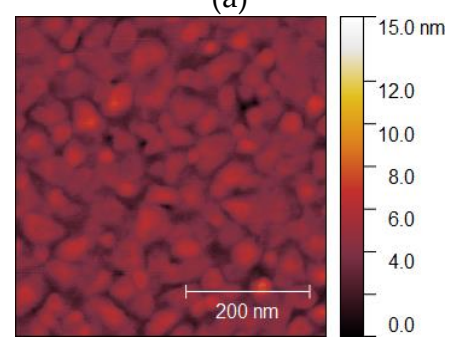

(d)

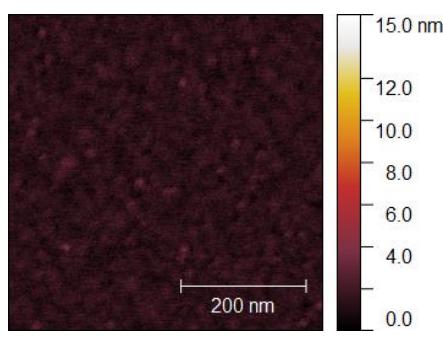

(b)

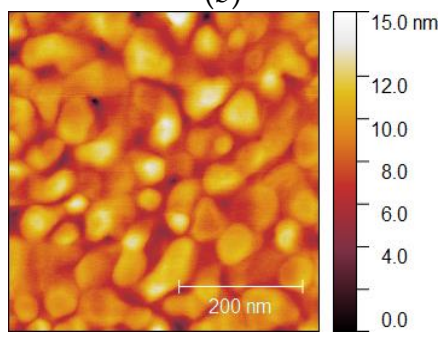

(e)

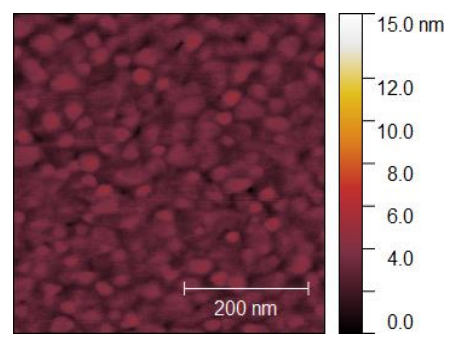

(c)

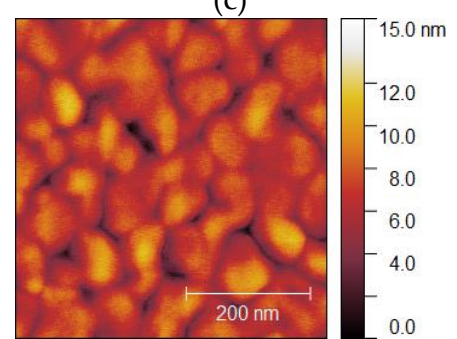

(f)

Figure 2. Typical atomic force microscope (AFM) images of Au thin films deposited on Si wafers: (a) before deposition; (b-f) deposited films with thicknesses of 15, 50, 100, 300, and $500 \mathrm{~nm}$, respectively.

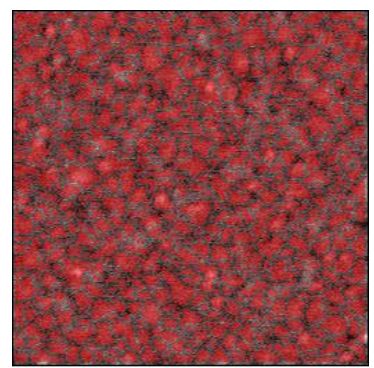

(a)

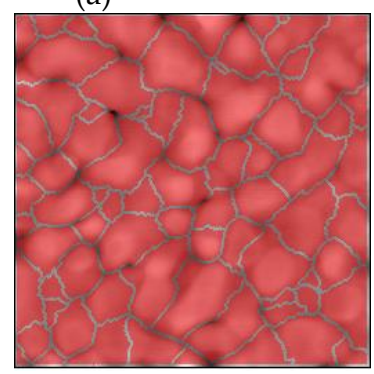

(d)

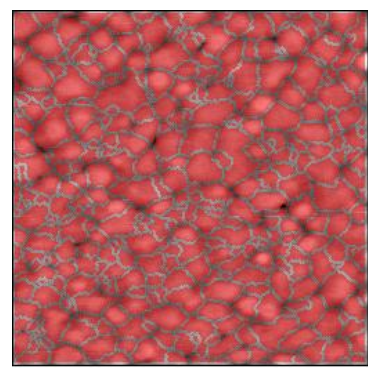

(b)

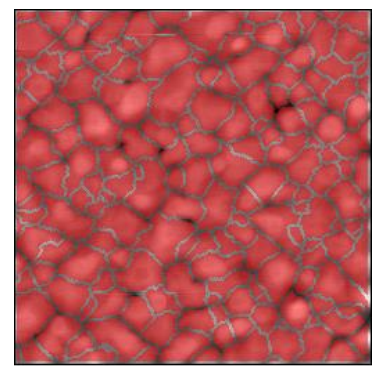

(c)

Figure 3. Typical AFM images of Au thin films deposited on Si wafers with grains segmented using the watershed algorithm: (a-e) films with thicknesses of 15, 50, 100, 300, and $500 \mathrm{~nm}$, respectively. 


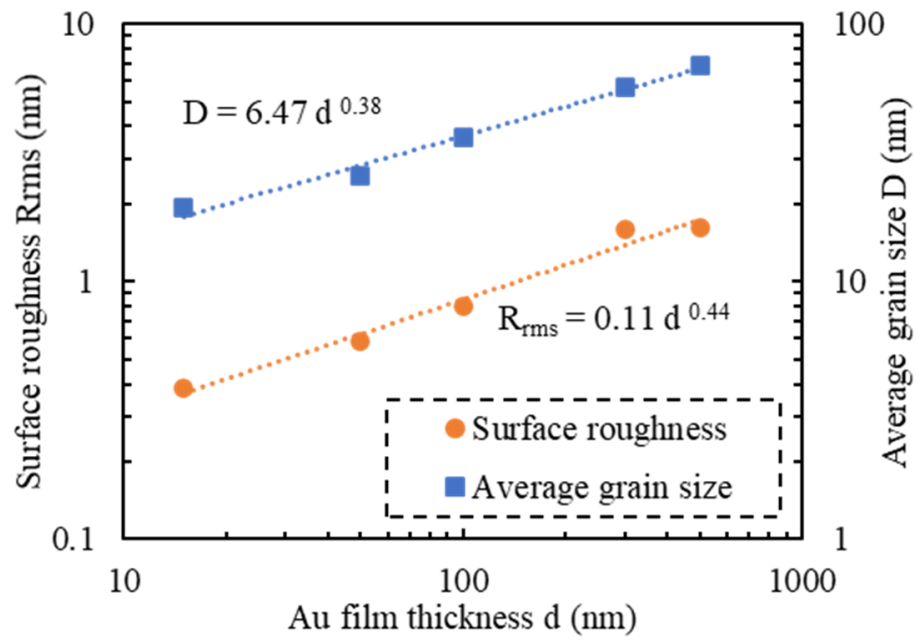

Figure 4. Effect of thickness of Au films deposited on Si wafers on surface roughness and average grain size.

In a previous study [43], the effect of surface roughness on spontaneous bonding was discussed in terms of elastic deformation and energy gain due to bond formation. If bonding is to be achieved, the elastic energy must be smaller than the work of adhesion, $W_{A}$, i.e., the energy gain due to bond formation at the interface. If the surface profile is assumed to be a sinusoidal curve, the surface is assumed to be elastic, and wavelength $\lambda$ is assumed to correspond to the average grain size, the necessary surface roughness for pressureless bonding can be estimated using

$$
\frac{R_{r m s}^{2}}{\lambda}<\frac{2\left(1-v^{2}\right)}{\pi E} \cdot W_{A}
$$

where $R_{r m s}$ and $\lambda$ are the RMS surface roughness and wavelength of the bonding surface. $E$ and $v$ are Young's modulus and Poisson's ratio. The relationship between average grain size and surface roughness calculated with this formula is shown in Figure 5. The measured average grain size and surface roughness of $\mathrm{Au}$ thin films with different thicknesses are also plotted. A thickness of $100 \mathrm{~nm}$ or less satisfied the above assumptions, and pressureless bonding should thus be achieved.

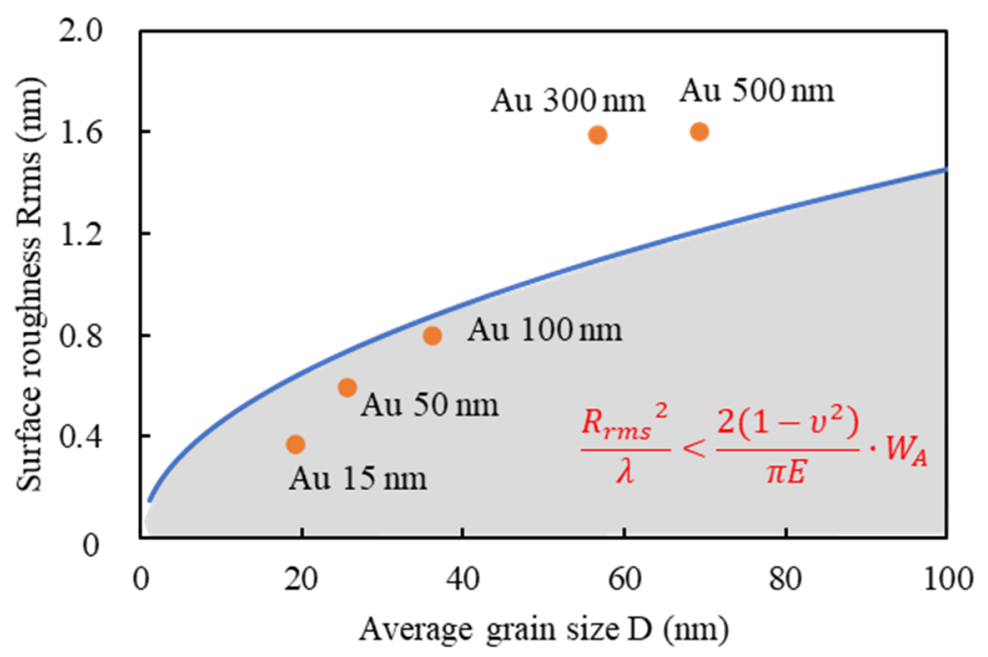

Figure 5. Relationship between surface roughness calculated using Equation (2) and average grain size. Measured average grain size and surface roughness of Au thin films with different thicknesses are also plotted. 
The measured film stress is plotted in Figure 6. Previous studies reported that the residual stress strongly depended on the sputtering parameters, especially the chamber pressure [44-46]. In this experiment, the film stress was compressive for all film thicknesses, and the compressive residual stress decreased to $-20 \mathrm{MPa}$ when the film thickness was increased to $500 \mathrm{~nm}$. Moreover, the change in the wafer bow after film deposition was less than $1 \mu \mathrm{m}$. This means that film stress and wafer bow due to residual stress in Au thin films should not affect bonding.

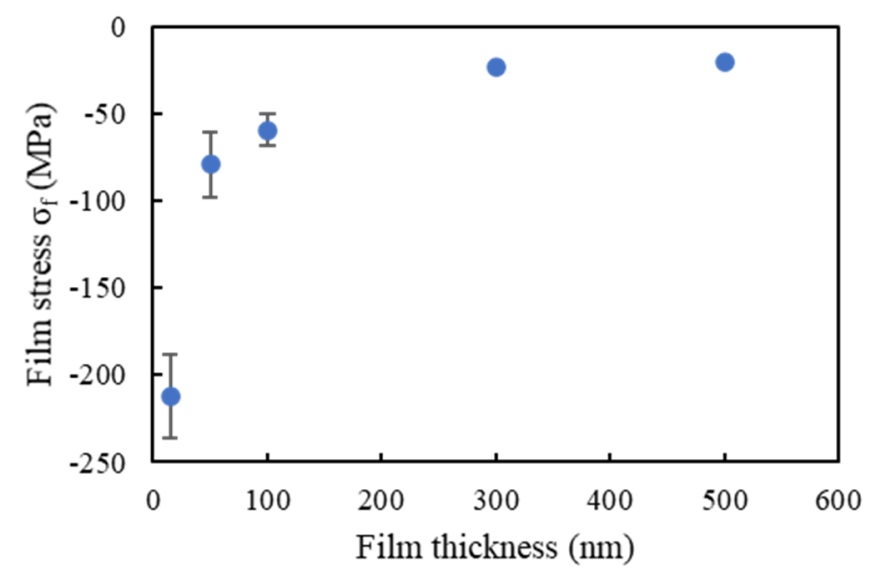

Figure 6. Residual stress in Au thin films as a function of film thickness.

The bonded area of the room-temperature pressureless bonded wafers was observed with the SAM. Typical SAM measurement results are shown in Figure 7. Most of the wafer, except for the particles, was bonded successfully when Au thin films with a thickness of $100 \mathrm{~nm}$ or less were used. As shown in Figure 8, the bonded area was inversely proportional to the Au film thickness. When the film thickness was 15,50,100, or $300 \mathrm{~nm}$, there was a sufficient bonding area for a razor blade test. Sufficient bonding strength over the surface energy of bulk Si $\left(2.5 \mathrm{~J} / \mathrm{m}^{2}\right)$ [47] was obtained using Au thin films with a thickness of less than or equal to $300 \mathrm{~nm}$ although the entire wafer was not bonded when the thickness was $300 \mathrm{~nm}$. 


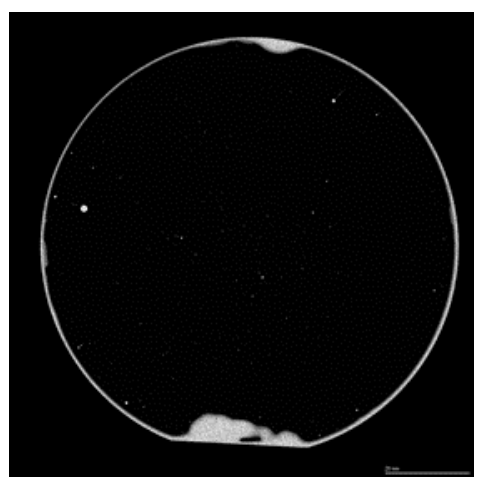

(a)

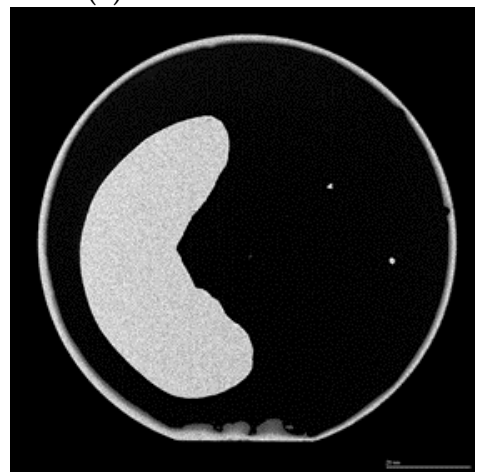

(d)

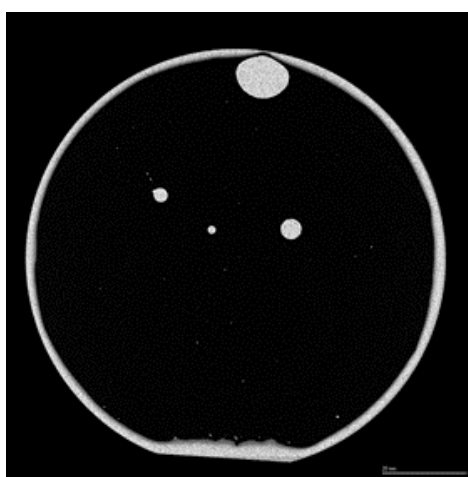

(b)

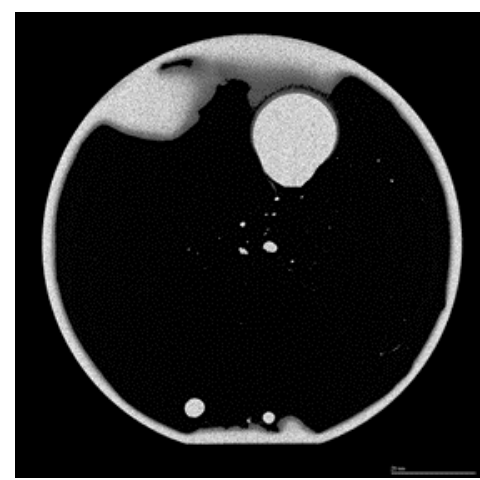

(c)

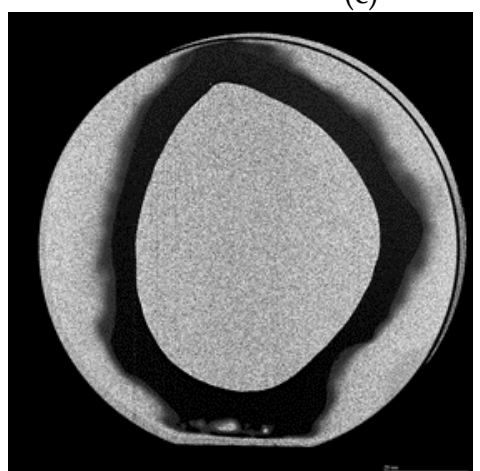

(e)

Figure 7. Typical surface acoustic microscope (SAM) images of room-temperature pressureless wafer-scale bonding with Au film thicknesses of (a-e) 15, 50, 100, 300, and $500 \mathrm{~nm}$, respectively.

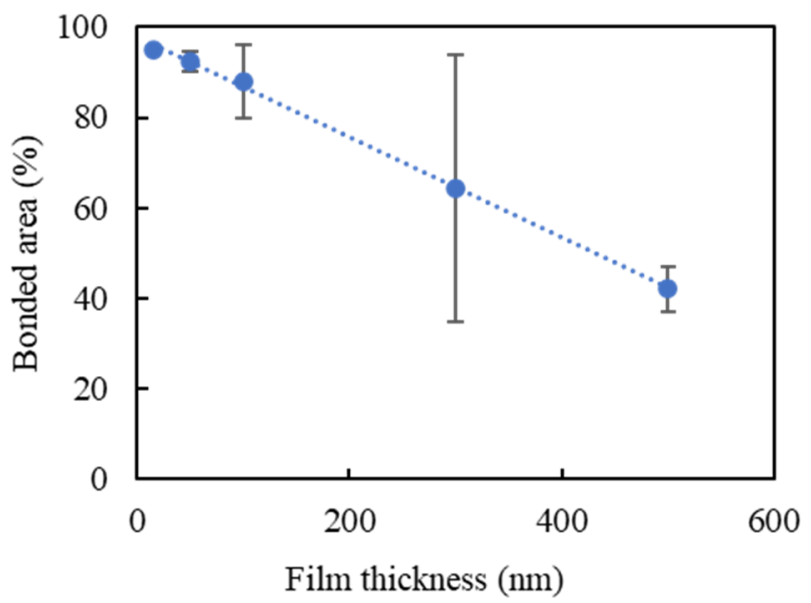

Figure 8. Relationship between bonded area and Au film thickness.

\subsection{Room-Temperature Wafer Sealing in Vacuum}

Measured AFM images of Au thin films with thicknesses of 15, 50, 100, $300 \mathrm{~nm}$ deposited on Si wafers with cavities and glass wafers are shown in Figures 9 and 10. The RMS surface roughness of the $\mathrm{Si}$ and glass wafers before film deposition was $0.2 \mathrm{~nm}$. The AFM measurement results showed that the change in surface roughness due to wet chemical etching was small, and thus, had little effect on bonding. The grain geometry of each Au thin film was determined using the watershed algorithm. AFM images of Au thin films deposited on Si wafers with cavities with the grains segmented are shown in Figures 11 and 12. The relationships between Au film thickness, surface roughness, and average grain size are plotted in Figure 13. The surface roughness and grain size increased exponentially as the 
film thickness was increased, which was consistent with the results when Au thin films were deposited on Si wafers (Figure 4).

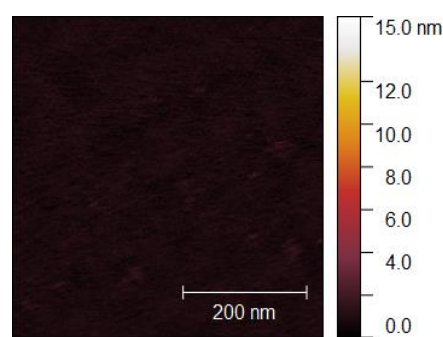

(a)

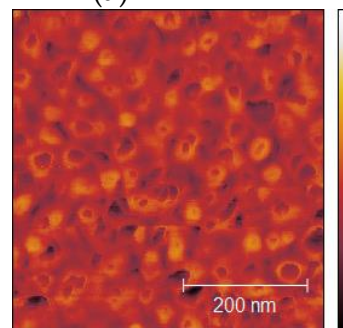

(d)

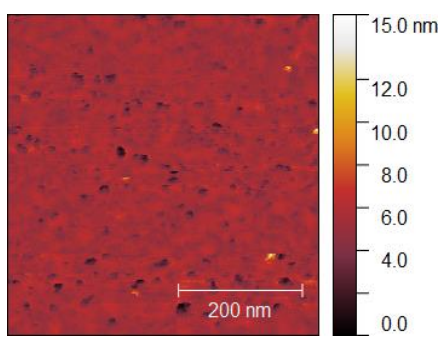

(b)

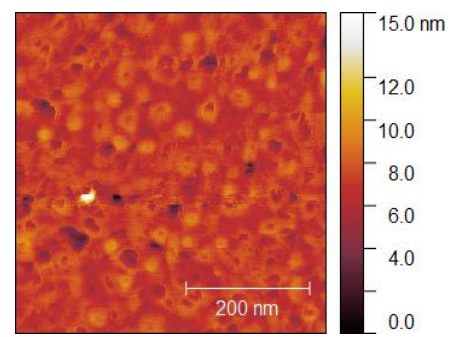

(c)

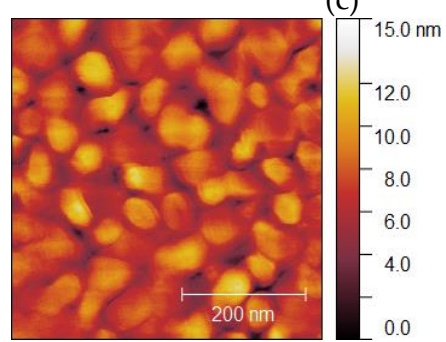

(e)

Figure 9. Typical AFM images of Au thin films deposited on Si wafers with cavities: (a) before deposition; (b-e) after deposition of films with thicknesses of 15, 50, 100, and $300 \mathrm{~nm}$, respectively.

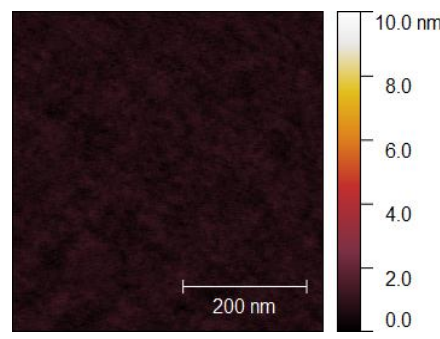

(a)

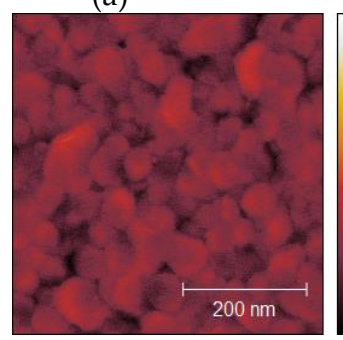

(d)

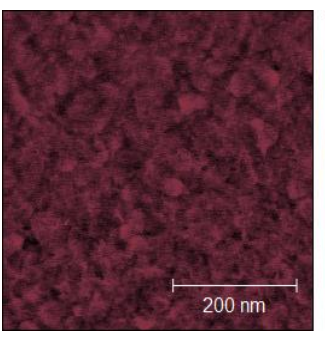

(b)
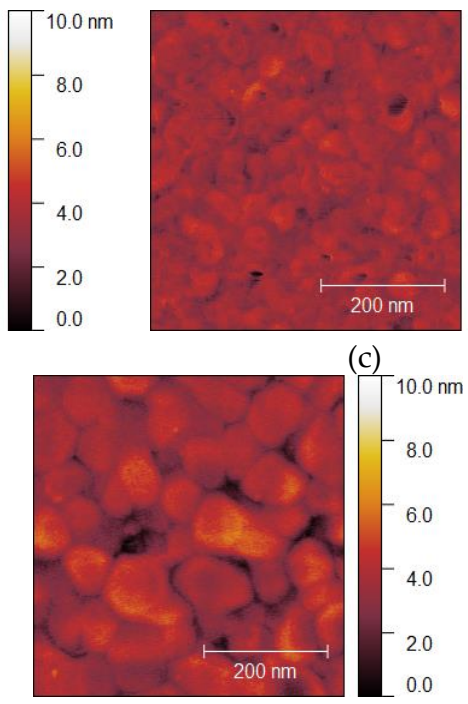

(e)

Figure 10. Typical AFM images of Au thin films deposited on glass wafers: (a) before deposition; (b-e) after deposition of films with thicknesses of 15, 50, 100, $300 \mathrm{~nm}$, respectively. 


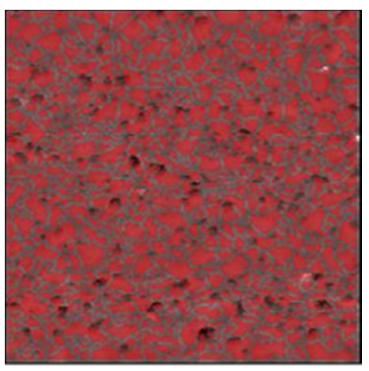

(a)

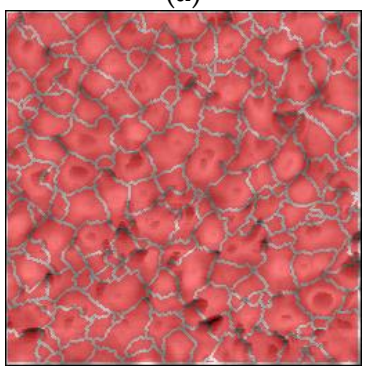

(c)

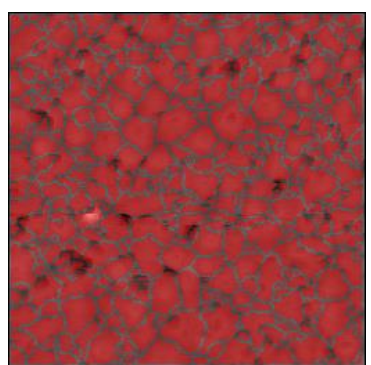

(b)

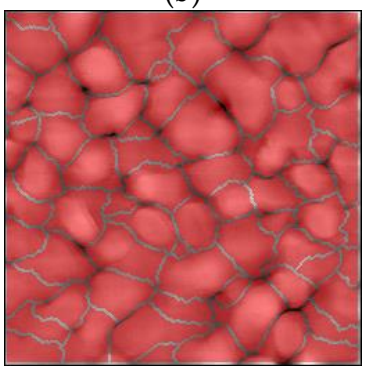

(d)

Figure 11. AFM images of Au thin films deposited on $\mathrm{Si}$ wafers with cavities with grains segmented using the watershed algorithm: (a-d) films with thicknesses of 15, 50, 100, $300 \mathrm{~nm}$, respectively.

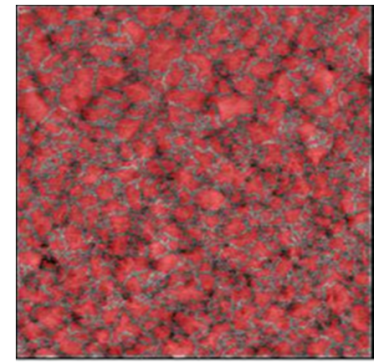

(a)

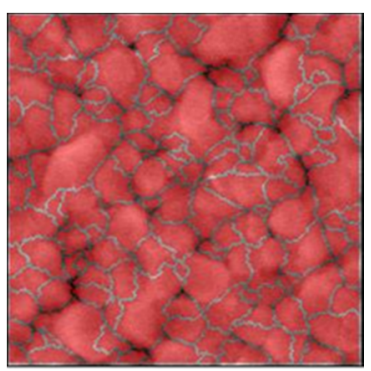

(c)

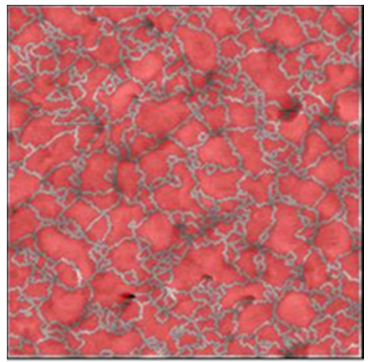

(b)

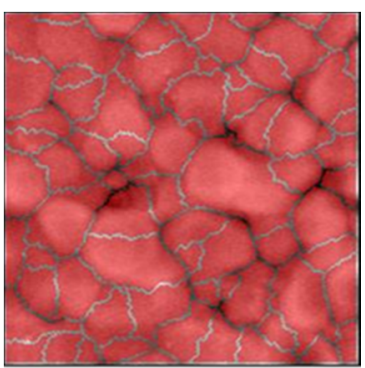

(d)

Figure 12. AFM images of Au thin films deposited on glass wafers with grains segmented using the watershed algorithm: (a-d) films with thicknesses of 15, 50, 100, $300 \mathrm{~nm}$, respectively. 


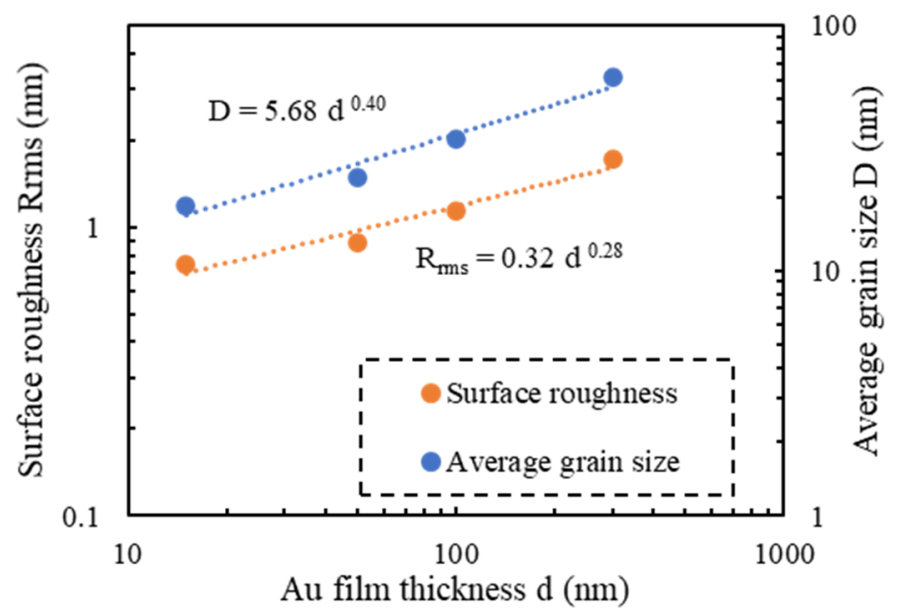

(a)

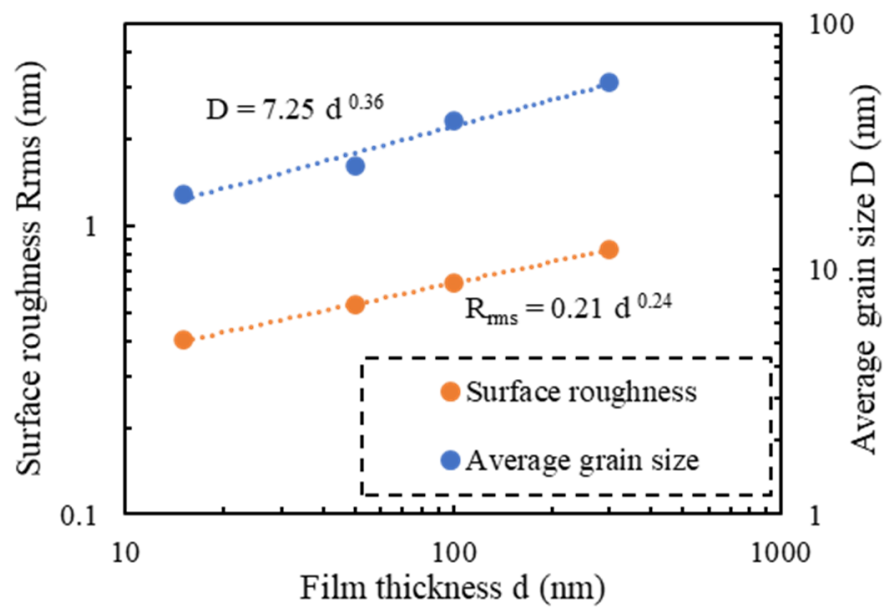

(b)

Figure 13. Effect of Au film thickness on surface roughness and average grain size: (a) films deposited on Si wafers with cavities; (b) films deposited on glass wafers.

The success or failure of the vacuum sealing was determined by observing the deflection of the glass caps caused by the differential pressure between the vacuum-sealed cavities and the ambient atmosphere. The measurement results are plotted in Figure 14. When the Au thin films were $100 \mathrm{~nm}$ thick or more, the deflection was observed only in the center region of the wafer immediately after bonding, and the deflection disappeared as the bonded wafer pairs were exposed to air. When the films were $50 \mathrm{~nm}$ thick or less, the deflection did not change even after 150 days of air exposure. These results indicated that Au thin films with a thickness of $50 \mathrm{~nm}$ or less could be used effectively for wafer bonding, especially for vacuum sealing. 


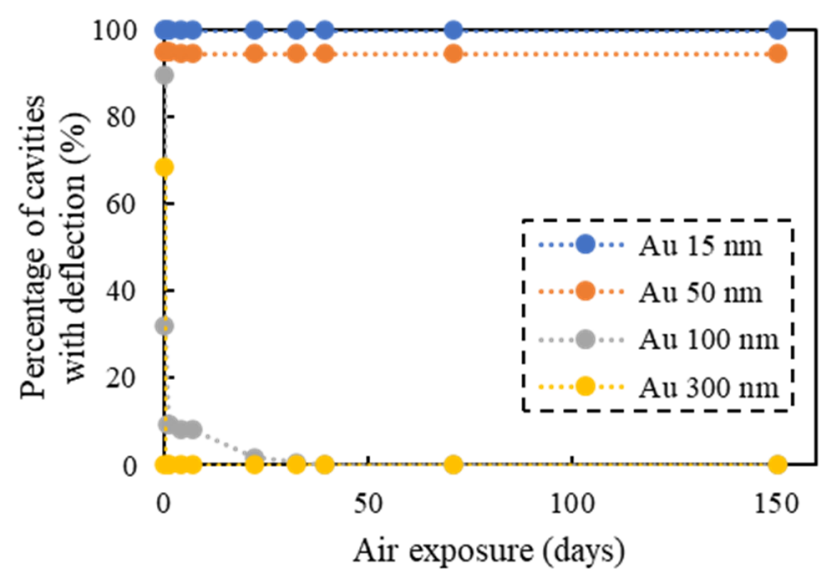

Figure 14. Vacuum sealing results: percentage of cavities with a deflection after air exposure.

Moreover, the air leakage of samples vacuum sealed using Au thin films with a thickness of $15 \mathrm{~nm}$ measured by the time dependence of the deflection of the thin glass caps was less than $1.3 \times 10^{-14} \mathrm{~Pa} \mathrm{~m}^{3} / \mathrm{s}$ [35]. This satisfied the reject limit defined by MIL-STD-883 K, method 1014 $\left(5.0 \times 10^{-9} \mathrm{~Pa} \mathrm{~m}^{3} / \mathrm{s}\right)$.

Cross-sectional TEM observation of the Au-Au bonded interface with 15-nm-thick Au films was performed to investigate its microstructure. The example TEM image in Figure 15 shows that bonding was achieved at the atomic level and that Au atoms diffused around the grain boundaries. This indicated that good sealing could be obtained using 15-nm-thick Au films.

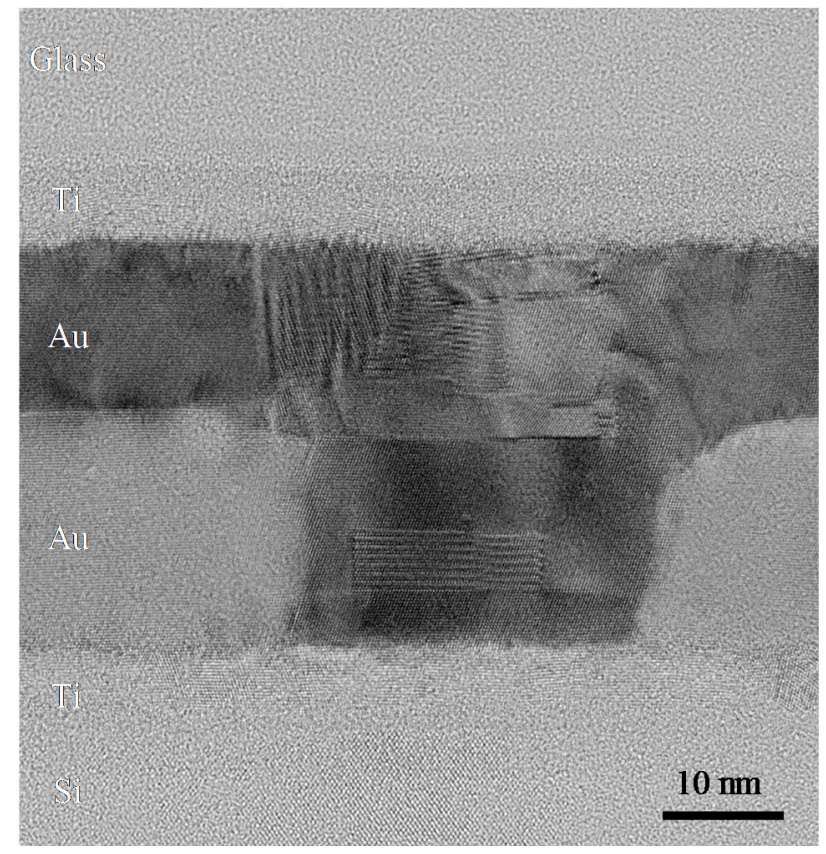

Figure 15. Transmission electron microscope (TEM) image of the bonded sample with a 15-nm-thick Au film.

\section{Conclusions}

We investigated the effect of Au film thickness (15-500 nm) and surface roughness on room-temperature pressureless wafer bonding and sealing by Au-Au surface activated bonding. The RMS surface roughness and grain size of Au thin films sputtered on Si wafers, Si wafers with cavities, and glass wafers increased with the film thickness. When the film thickness was $100 \mathrm{~nm}$ or less, most of the wafer was bonded; the bonded area decreased as the Au film thickness was increased. 
Room-temperature wafer-scale vacuum sealing was achieved using Au thin films with a thickness of $50 \mathrm{~nm}$ or less. These results suggest that Au-Au surface activated bonding using ultrathin Au films is useful in achieving room-temperature wafer-level hermetic and vacuum packaging of MEMS and optoelectronic devices.

Author Contributions: Investigation: M.Y., T.M., Y.K., H.T., T.S., S.T., T.I., and E.H.; Methodology: M.Y. and E.H.; Validation: M.Y.; Data curation: M.Y.; Writing—original draft: M.Y.: Writing—review \& editing: T.M., Y.K., H.T., T.S., S.T., T.I., and E.H.; Funding acquisition: T.H. and E.H.; Resources: H.T., T.S., S.T., T.I., and E.H.; Supervision: T.S., T.I., and E.H.; Project administration: E.H. All authors have read and agreed to the published version of the manuscript.

Funding: This research received no external funding.

Acknowledgments: The authors would like to thank Nippon Electric Glass Co., Ltd. for providing the glass wafers used in the wafer-sealing experiment.

Conflicts of Interest: The authors declare no conflicts of interest.

\section{References}

1. Higurashi, E. Heterogeneous integration based on low-temperature bonding for advanced optoelectronic devices. Jpn. J. Appl. Phys. 2018, 57, 04FA02. [CrossRef]

2. Higurashi, E.; Suga, T. Review of Low-Temperature Bonding Technologies and Their Application in Optoelectronic Devices. Electron. Commun. Jpn. 2016, 99, 63-71. [CrossRef]

3. Higurashi, E.; Sawada, R.; Suga, T. Optical Microsensors Integration Technologies for Biomedical Applications. IEICE Trans. Electron. 2009, 231-238. [CrossRef]

4. Tanaka, S. Wafer-level hermetic MEMS packaging by anodic bonding and its reliability issues. Microelectron. Reliab. 2014, 54, 875-881. [CrossRef]

5. Tan, C.S.; Fan, J.; Lim, D.F.; Chong, G.Y.; Li, H. Low temperature wafer-level bonding for hermetic packaging of 3D microsystems. J. Micromech. Microeng. 2011, 21, 75006. [CrossRef]

6. Henmi, H.; Shoji, S.; Shoji, Y.; Yoshimi, K.; Esashi, M. Vacuum packaging for microsensors by glass-silicon anodic bonding. Sens. Actuators A Phys. 1994, 43, 243-248. [CrossRef]

7. Tanaka, K.; Hirano, H.; Kumano, M.; Froemel, J.; Tanaka, S. Bonding-Based Wafer-Level Vacuum Packaging Using Atomic Hydrogen Pre-Treated Cu Bonding Frames. Micromachines 2018, 9, 181. [CrossRef] [PubMed]

8. Higurashi, E.; Kawai, H.; Suga, T.; Okada, S.; Hagihara, T. Low-Temperature Solid-State Bonding Using Hydrogen Radical Treated Solder for Optoelectronic and MEMS Packaging. ECS Trans. 2014, 64, 267-274. [CrossRef]

9. Goyal, A.; Cheong, J.; Tadigadapa, S. Tin-based solder bonding for MEMS fabrication and packaging applications. J. Micromech. Microeng. 2004, 14, 819-825. [CrossRef]

10. Wang, Q.; Choa, S.-H.; Kim, W.; Hwang, J.; Ham, S.; Moon, C. Application of Au-Sn eutectic bonding in hermetic radio-frequency microelectromechanical system wafer level packaging. J. Electron. Mater. 2006, 35, 425-432. [CrossRef]

11. Tsau, C.; Spearing, S.; Schmidt, M.A. Characterization of Wafer-Level Thermocompression Bonds. J. Microelectromech. Syst. 2004, 13,963-971. [CrossRef]

12. Taklo, M.M.V.; Storås, P.; Schjølberg-Henriksen, K.; Hasting, H.K.; Jakobsen, H. Strong, high-yield and low-temperature thermocompression silicon wafer-level bonding with gold. J. Micromech. Microeng. 2004, 14, 884-890. [CrossRef]

13. Park, G.-S.; Kim, Y.-K.; Paek, K.-K.; Kim, J.-S.; Lee, J.-H.; Ju, B.-K. Low-Temperature Silicon Wafer-Scale Thermocompression Bonding Using Electroplated Gold Layers in Hermetic Packaging. Electrochem. Solid State Lett. 2005, 8, G330. [CrossRef]

14. Shimatsu, T.; Uomoto, M.; Oba, K.; Furukata, Y. Atomic diffusion bonding of wafers in air with thin Au films and its application to optical devices fabrication. In Proceedings of the 2012 3rd IEEE International Workshop on Low Temperature Bonding for 3D Integration, Tokyo, Japan, 22-23 May 2012; p. 103. [CrossRef]

15. Goorsky, M.; Schjølberg-Henriksen, K.; Beekley, B.; Bai, T.; Mani, K.; Ambhore, P.; Bajwa, A.; Malik, N.; Iyer, S.S. Characterization of interfacial morphology of low temperature, low pressure $\mathrm{Au}-\mathrm{Au}$ thermocompression bonding. Jpn. J. Appl. Phys. 2017, 57, 02BC03. [CrossRef] 
16. Matsumae, T.; Kurashima, Y.; Umezawa, H.; Mokuno, Y.; Takagi, H. Room-temperature bonding of single-crystal diamond and $\mathrm{Si}$ using $\mathrm{Au} / \mathrm{Au}$ atomic diffusion bonding in atmospheric air. Microelectron. Eng. 2018, 195, 68-73. [CrossRef]

17. Okada, H.; Itoh, T.; Frömel, J.; Gessner, T.; Suga, T. Room temperature vacuum sealing using surfaced activated bonding with $\mathrm{Au}$ thin films. In Proceedings of the 13th International Conference on Solid-State Sensors, Actuators and Microsystems, 2005. Digest of Technical Papers. TRANSDUCERS '05, Seoul, Korea, 5-9 June 2005; Volume 1, pp. 932-935. [CrossRef]

18. Higurashi, E.; Imamura, T.; Suga, T.; Sawada, R. Low-Temperature Bonding of Laser Diode Chips on Silicon Substrates Using Plasma Activation of Au Films. IEEE Photonics Technol. Lett. 2007, 19, 1994-1996. [CrossRef]

19. Takigawa, R.; Higurashi, E.; Suga, T.; Shinada, S.; Kawanishi, T. Low-temperature Au-to-Au Bonding for $\mathrm{LiNbO}_{3} / \mathrm{Si}$ Structure Achieved in Ambient Air. IEICE Trans. Electron. 2007, E90-C, 145-146. [CrossRef]

20. Takigawa, R.; Higurashi, E.; Suga, T.; Sawada, R. Room-Temperature Bonding of Vertical-Cavity Surface-Emitting Laser Chips on Si Substrates Using Au Microbumps in Ambient Air. Appl. Phys. Express 2008, 1, 112201. [CrossRef]

21. Higurashi, E.; Chino, D.; Suga, T.; Sawada, R. Au-Au Surface-Activated Bonding and Its Application to Optical Microsensors With 3-D Structure. IEEE J. Sel. Top. Quantum Electron. 2009, 15, 1500-1505. [CrossRef]

22. Takigawa, R.; Higurashi, E.; Suga, T.; Kawanishi, T. Passive Alignment and Mounting of $\mathrm{LiNbO}_{3}$ Waveguide Chips on Si Substrates by Low-Temperature Solid-State Bonding of Au. IEEE J. Sel. Top. Quantum Electron. 2011, 17, 652-658. [CrossRef]

23. Higurashi, E.; Fukunaga, T.; Suga, T. Low-Temperature Bonding of GaN on Si Using a Nonalloyed Metal Ohmic Contact Layer for GaN-Based Heterogeneous Devices. IEEE J. Quantum Electron. 2011, 48, 182-186. [CrossRef]

24. Yamamoto, S.-I.; Higurashi, E.; Suga, T.; Sawada, R. Low-temperature hermetic packaging for microsystems using Au-Au surface-activated bonding at atmospheric pressure. J. Micromech. Microeng. 2012, 22, 55026. [CrossRef]

25. Kurashima, Y.; Maeda, A.; Takigawa, R.; Takagi, H. Room temperature wafer bonding of metal films using flattening by thermal imprint process. Microelectron. Eng. 2013, 112, 52-56. [CrossRef]

26. Kurashima, Y.; Maeda, A.; Takagi, H. Replication of atomically smooth surface shape onto electroplated Au patterns by lift-off process and room-temperature $\mathrm{Au}-\mathrm{Au}$ bonding in atmospheric air. Microelectron. Eng. 2014, 129, 1-4. [CrossRef]

27. Goto, M.; Hagiwara, K.; Iguchi, Y.; Ohtake, H.; Saraya, T.; Higurashi, E.; Toshiyoshi, H.; Hiramoto, T. 3-D Silicon-on-Insulator Integrated Circuits With NFET and PFET on Separate Layers Using $\mathrm{Au} / \mathrm{SiO}_{2} \mathrm{Hybrid}$ Bonding. IEEE Trans. Electron Devices 2014, 61, 2886-2892. [CrossRef]

28. Kurashima, Y.; Maeda, A.; Takagi, H. Room-temperature wafer scale bonding using smoothed Au seal ring surfaces for hermetic sealing. Jpn. J. Appl. Phys. 2015, 55, 16701. [CrossRef]

29. Higurashi, E.; Yamamoto, M.; Sato, T.; Suga, T.; Sawada, R. Room-Temperature Gold-Gold Bonding Method Based on Argon and Hydrogen Gas Mixture Atmospheric-Pressure Plasma Treatment for Optoelectronic Device Integration. IEICE Trans. Electron. 2016, 339-345. [CrossRef]

30. Higurashi, E.; Okumura, K.; Kunimune, Y.; Suga, T.; Hagiwara, K. Room-Temperature Bonding of Wafers with Smooth Au Thin Films in Ambient Air Using a Surface-Activated Bonding Method. IEICE Trans. Electron. 2017, 156-160. [CrossRef]

31. Kurashima, Y.; Matsumae, T.; Takagi, H. Room-temperature Au-Au bonding in atmospheric air using direct transferred atomically smooth Au film on electroplated patterns. Microelectron. Eng. 2018, 189, 1-5. [CrossRef]

32. Shiratori, Y.; Hoshi, T.; Ida, M.; Higurashi, E.; Matsuzaki, H. High-Speed InP/InGaAsSb DHBT on High-Thermal-Conductivity SiC Substrate. IEEE Electron Device Lett. 2018, 39, 807-810. [CrossRef]

33. Yamamoto, M.; Higurashi, E.; Suga, T.; Sawada, R.; Itoh, T. Properties of various plasma surface treatments for low-temperature Au-Au bonding. Jpn. J. Appl. Phys. 2018, 57, 04FC12. [CrossRef]

34. Yamamoto, M.; Matsumae, T.; Kurashima, Y.; Takagi, H.; Suga, T.; Itoh, T.; Higurashi, E. Comparison of Argon and Oxygen Plasma Treatments for Ambient Room-Temperature Wafer-Scale Au-Au Bonding Using Ultrathin Au Films. Micromachines 2019, 10, 119. [CrossRef] [PubMed] 
35. Yamamoto, M.; Kunimune, Y.; Matsumae, T.; Kurashima, Y.; Takagi, H.; Iguchi, Y.; Honda, Y.; Suga, T.; Itoh, T.; Higurashi, E. Room-temperature pressureless wafer-scale hermetic sealing in air and vacuum using surface activated bonding with ultrathin Au films. Jpn. J. Appl. Phys. 2019, 59, SBBB01. [CrossRef]

36. Klapetek, P.; Ohlídal, I.; Montaigne-Ramil, A.; Bonanni, A.; Stifter, D.; Sitter, H. Atomic Force Microscopy Characterization of ZnTe Epitaxial Thin Films. Jpn. J. Appl. Phys. 2003, 42, 4706-4709. [CrossRef]

37. Stoney, G.G. The tension of metallic films deposited by electrolysis. Proc. R. Soc. London. Ser. A Math. Phys. Sci. 1909, 82, 172-175. [CrossRef]

38. Fournel, F.; Continni, L.; Morales, C.; Da Fonseca, J.; Moriceau, H.; Rieutord, F.; Barthélémy, A.; Radu, I. Measurement of bonding energy in an anhydrous nitrogen atmosphere and its application to silicon direct bonding technology. J. Appl. Phys. 2012, 111, 104907. [CrossRef]

39. Brantley, W.A. Calculated elastic constants for stress problems associated with semiconductor devices. J. Appl. Phys. 1973, 44, 534. [CrossRef]

40. Available online: http://imagej.nih.gov/ij/ (accessed on 25 April 2020).

41. Maszara, W.P.; Goetz, G.; Caviglia, A.; McKitterick, J.B. Bonding of Silicon Wafers for Silicon-on-Insulator. J. Appl. Phys. 1988, 64, 4943-4950. [CrossRef]

42. Zhang, X.; Song, X.H.; Zhang, D.L. Thickness Dependence of Grain Size and Surface Roughness for DC Magnetron Sputtered Au Films. Chin. Phys. B 2010, 19, 086802. [CrossRef]

43. Takagi, H.; Maeda, R.; Chung, T.R.; Hosoda, N.; Suga, T. Effect of Surface Roughness on Room-Temperature Wafer Bonding by Ar Beam Surface Activation. Jpn. J. Appl. Phys. 1998, 37, 4197-4203. [CrossRef]

44. Tan, C.W.; Miao, J. Optimization of Sputtered Cr/Au Thin Film for Diaphragm-Based MEMS Applications. Thin Solid Films 2009, 517, 4921-4925. [CrossRef]

45. Abadias, G.; Chason, E.; Keckes, J.; Sebastiani, M.; Thompson, G.B.; Barthel, E.; Doll, G.L.; Murray, C.E.; Stoessel, C.H.; Martinu, L. Review Article: Stress in Thin Films and Coatings: Current Status, Challenges, and Prospects. J. Vac. Sci. Technol. A Vac. Surf. Film 2018, 36, 020801. [CrossRef]

46. Hoffman, D.W.; Thornton, J.A. Internal Stresses in Cr, Mo, Ta, and Pt Films Deposited by Sputtering from a Planar Magnetron Source. J. Vac. Sci. Technol. 1982, 20, 355-358. [CrossRef]

47. Tong, Q.-Y.; Kim, W.J.; Lee, T.; Gösele, U. Low Vacuum Wafer Bonding. Electrochem. Solid-State Lett. 1999, 1, 52-53. [CrossRef]

(C) 2020 by the authors. Licensee MDPI, Basel, Switzerland. This article is an open access article distributed under the terms and conditions of the Creative Commons Attribution (CC BY) license (http://creativecommons.org/licenses/by/4.0/). 